\title{
Animal owners' appraisal of large carnivore presence and use of interventions to prevent carnivore attacks on domestic animals in Sweden
}

\author{
Ann Eklund ${ }^{1,2}$ (D) Anders Flykt ${ }^{3} \cdot$ Jens Frank $^{1} \cdot$ Maria Johansson $^{2}$ \\ Received: 23 May 2019 / Revised: 6 February 2020 / Accepted: 17 February 2020 / Published online: 12 March 2020 \\ (C) The Author(s) 2020
}

\begin{abstract}
Large carnivores elicit strong emotional reactions, which could influence consensus or social conflicts between persons promoting wildlife conservation and people who suffer from its negative consequences. Interventions to prevent carnivore attacks on domestic animals are intended to promote coexistence between people and carnivores, but could fail to mitigate fear and social conflicts if emotions and perspectives of intervention end users are not given careful consideration. We conducted focus group interviews with animal owners in Sweden and applied a framework of the appraisal theory of emotion to gain a nuanced understanding of their appraisal of intervention use. The analysis identified that appraisals occur at two different levels. The first process related to appraisals of carnivore presence and the second process related to appraisals of intervention use. The interventions can provide an opportunity to facilitate the animal owners' coping with carnivore presence and thereby reduce their experienced anxiety of carnivore attacks. However, if animal owners are presented with interventions which they consider irrelevant, that have implications with which they cannot cope, or that are incongruent with the animal owners' norms, then the promotion of interventions can also generate frustration and negative emotions. As such, interventions have the potential to either mitigate or undermine wildlife-related conflicts. In the wider context, taking the perspective of the individual becomes essential, and animal owners' experiences and appraisals of intervention use must be acknowledged to allow development of social trust and empathetic dialog between stakeholders in the future.
\end{abstract}

Keywords Appraisal theory $\cdot$ Emotion $\cdot$ Large carnivore $\cdot$ Livestock $\cdot$ Conservation $\cdot$ Wildlife conflict

\section{Introduction}

Biodiversity conservation has received increasing attention over recent decades, with warnings of species declines and

Electronic supplementary material The online version of this article (https://doi.org/10.1007/s10344-020-1369-0) contains supplementary material, which is available to authorized users.

Ann Eklund

ann.eklund@slu.se; ann.eklund@arkitektur.lth.se

1 Grimsö Wildlife Research Station, Department of Ecology, Swedish University of Agricultural Sciences, SE-730

91 Riddarhyttan, Sweden

2 Environmental Psychology, Department of Architecture and Built Environment, Lund University, PO Box 118, SE-221

00 Lund, Sweden

3 Department of Psychology and Social Work, Mid Sweden University, SE-831 25 Ostersund, Sweden extinctions (e.g., Barnosky et al. 2011; Dirzo et al. 2014). In an increasingly human-dominated landscape, the success of conservation projects often implies that wildlife ranges and human practices must overlap geographically (Carter et al. 2012; Johansson et al. 2016). This co-occurrence can lead to positive interactions between people and wildlife, but in some cases, interactions of a more negative kind may occur (Dirzo et al. 2014; Woodroffe et al. 2005). Large carnivores (hereafter "carnivores") can have negative impacts on human practices, for instance through predation on livestock and pets. A conflict of interests therefore arises between wildlife conservation and domestic animal husbandry, potentially eliciting strong emotional responses with consequential health implications for these stakeholders (Manfredo 2008), as each side experiences that the other side benefits at their expense (Redpath et al. 2013; Sjölander-Lindqvist 2008, 2009).

To mitigate the negative impact of carnivores on domestic animals, and subsequent conflict between stakeholders, many countries and organizations have developed compensation 
schemes to provide financial compensation for losses (e.g., Agarwala et al. 2010; Milheiras and Hodge 2011; Zabel and Holm-Müller 2008). However, previous research has established that financial compensation does not make stakeholders more positive toward carnivores (Naughton-Treves et al. 2003), suggesting that the lost animals do not simply represent a monetary or instrumental value to their owners. In many places, including Sweden, interventions intended to prevent carnivore attacks on domestic animals (hereafter "interventions") have therefore become prioritized in addition to compensation in an attempt to generate coexistence between carnivore conservation and animal husbandry.

There is currently limited scientific evidence of the effectiveness of interventions in reducing predation and conflict (van Eeden et al. 2018; Eklund et al. 2017; Treves et al. 2016). Some research has focused on estimates of intervention acceptance among stakeholders and the public (e.g., Bruskotter et al. 2009; Frank et al. 2015; Koval and Mertig 2010), which can be influenced by value orientations toward wildlife (Jacobs et al. 2014). However, to our knowledge, there is still little documentation that provides a more detailed understanding of the drivers and appraisals of interventions which lead to their opposition and acceptance among animal owners, who represent the intended end users. Taking this perspective of the individual is important to highlight end user considerations of intervention use, but also to gain an understanding of individual perspectives that feed into the context of collective responses to carnivore management and conservation (Sjölander-Lindqvist et al. 2015). Thus, obtaining knowledge of the detailed end user perspective for intervention use is essential for carnivore conservation and management built on mutual respect, trust, and understanding, which in turn is necessary to minimize fear and conflicts associated with large carnivores (Frank et al. 2015; Johansson et al. 2012; Redpath et al. 2013).

The aim of this study is to gain a nuanced understanding of the process behind animal owners' responses to intervention use and the potential of the interventions to facilitate coping in relation to carnivore presence. By approaching owners of different types of animals, we aim to understand the goals of different types of animal husbandry practices and their perceived unique situations in relation to large carnivores. By including different owner groups, we obtain perspectives on animal husbandry and carnivores from each group and avoid drawing conclusions for one group based on the experiences of others. Taking a qualitative approach, we analyze the animal owners' appraisals of intervention use to illustrate the psychological processes behind intervention acceptance or opposition. The qualitative analysis does not allow for quantitative comparisons of appraisals between owner groups, but rather attempts to capture the range of appraisals among animal owners broadly. The knowledge gained can thus be regarded as complementary to quantitative evaluations of intervention acceptance (Austin et al. 2010; Eklund et al. 2020).
We apply the framework of appraisal theory of emotion (Leventhal and Scherer 1987; Scherer et al. 2001) in our analysis, to examine the psychological process, in terms of appraisals, behind emotional outcomes such as fear, frustration, excitement etc. The appraisal process, as described by this theory, can in the context of the study be elicited by carnivore presence or the provision of interventions. According to the theory, the psychological appraisals that follow an event, such as carnivore presence in areas with domestic animals, can occur at varying cognitive levels of processing and does not require complex cognitive thought (Scherer 2009). Often, the process occurs effortlessly, and the animal owner would rapidly evaluate whether the carnivore presence is of relevance to her/his goals (Scherer 2009). If carnivore presence is indeed relevant, this event receives further attention, and its implications for the goals are evaluated, followed by a judgment of the personal ability to cope with these implications. Finally, the event is evaluated for norm compatibility and congruence with the owner's personal norms as well as experienced social norms. The weight and direction of each step in the evaluation process will likely vary with circumstances and individuals having different previous experiences and knowledge (Jacobs et al. 2013), why different animal owners may experience different emotional outcomes to the same situation. Some emotion outcomes, such as anxiety or fear, may generate a need for a response action which in turn can ignite new appraisal processes. In our case, the use of interventions represents this response to carnivore presence if animal owners are anxious about carnivore attacks. When interventions are implemented, they are appraised by the animal owners following the same structure as described above: is the intervention relevant to the goal of preventing carnivore attacks, are there implications of using the intervention, does the animal owner have a potential to cope with these implications, and is the intervention congruent with the animal owner's norms.

How animal owners appraise interventions will eventually influence their willingness to use interventions, but could also influence the relationship between animal owners and parties who advocate intervention use. Intervention use thereby has the potential to either mitigate or generate social conflict over carnivore conservation and management. To ensure mitigation of impact as well as conflict in carnivore conservation, emotional expressions and end user concerns and perspectives on intervention use should be given careful consideration before interventions are promoted (Manfredo 2008; Redpath et al. 2013). Providing wildlife managers, policy makers, and conservationists - often trained in ecology and learning the social aspects of their work by trial and error (Treves et al. 2006) - with an understanding of the animal owners' perceptions of these interventions is important for sustainable carnivore management. This kind of research could provide a foundation for empathy and constructive dialog between involved stakeholders about interventions (Treves et al. 2006; Wondra and Ellsworth 2015) and is important to ensure a sustainable 
work environment and continuation of domestic animal practices, and ultimately future human-carnivore coexistence. This is the scope of our study.

\section{Method}

\section{Participants}

This study involves five primary stakeholders that were identified based on statistics of carnivore attacks on domestic animals and national compensation schemes in Sweden (Frank et al. 2018). We gathered a total of 64 animal owners in three groups of sheep owners, one group of transhumance livestock farmers, three groups of hunters with dogs, one group of pet dog owners, and three groups of reindeer herders. These groups represent all owner groups that are likely to be at risk of suffering attacks from large carnivores on their animals in Sweden. Participants were recruited from the geographical regions where interactions between carnivores and domestic animals were most likely, based on the known distribution and presence of carnivore populations (Eklund et al. 2017b; Kindberg and Swenson 2018; Tovmo et al. 2016; Wabakken et al. 2016). Animal husbandry practices vary between groups as sheep in Sweden are generally kept in fenced pastures, while transhumance farming implies that livestock are grazing freely in the forest during the summer, and reindeer are kept as semi-domestic free roaming herds. Hunting dogs are traditionally loose during hunts, whereas pet dogs can be on or off a leash. Subgroups were also created among sheep owners based on herd sizes. Hunter subgroups were based on the use of different types of dogs, game, and hunting techniques, and reindeer herder subgroups were based on type of reindeer herding practice (mountain, forest, or concession).

\section{Interviews}

Data was collected in 11 focus group interviews, each $2-3 \mathrm{~h}$ long, with approximately 6-8 participants in each group. A focus group setting was considered suitable as the topic of intervention use was not considered personally sensitive, and elaborate group discussions can provide benefits of detail and breadth to enhance our understanding of various aspects of intervention use (Parker and Tritter 2006; Robson 2011).

The interviews were divided into two parts: the first included a discussion around animal keeping and intervention use, and the second part put focus on interventions as a strategy to cope with the carnivore threat. Interviews followed a semi-structured interview guide (see outline in Supplementary materials), with general introductory enquiries about participants and their animal keeping. Key questions focused on the participants' use of interventions: what interventions they had heard of or used and where they receive information and funding.

Halfway through the interviews, we introduced visual material to facilitate discussions (Harper 2002) regarding the participants' experience and perspectives on approximately 20 interventions. Each intervention was presented on a card with a picture and a description of the intended function. Proposed interventions were the same within, but varied slightly between, owner groups (Supplementary Table 1). Participants were asked if they would consider using the interventions or not and give reasons for their decision. In cases where participants were already using interventions, they were asked to give more detail on their choice of intervention and its functionality in their everyday life.

\section{Procedure}

Participants were recruited via the largest national member organizations among sheep owners (Swedish Sheep Breeders Association), transhumance farmers (Association of Swedish Transhumance), and hunters (Swedish Hunters Association and the Hunters' National Association). Reindeer owners were also working as herders and were recruited via the Swedish Sami National Association, the Concession Sami Villages Economic Association, and directly via the Sami villages' representatives. Contact persons within the organizations recruited participants and forwarded their contact details to the research team. To avoid previously established roles to limit the discussions, we attempted to recruit participants with no formal leadership role within their organizations (i.e., board members). Pet dog owners were recruited through personal contacts and were acquaintances or neighbors of the research team's colleagues. Two previous attempts to recruit pet dog owners via the Kennel Club and one attempt via the local dog training centers failed and led to the different approach in recruiting participants for this focus group. A formal written invitation was sent to participants by email. Invitations briefly described the project aim to discuss interventions, with the aim of summarizing how the users perceive them.

The venues were meeting rooms in, e.g., community centers, a hotel, and in one case a university meeting room. On arrival, the participants were informed of their voluntary participation and that they were free to withdraw at any time without consequences. We received consent from all participants, and everyone agreed to the digital recording. All information given during and in connection to the interviews was treated confidentially and handled in accordance with regulations for the protection of personal data.

\section{The study area}

Participants were recruited from regions where carnivore interactions were most likely. Interviewed sheep owners were active in Uppsala, Örebro, and Värmland counties; hunters 
with dogs were active mainly in Värmland and Dalarna counties and pet dog owners in Örebro county. Within these regions, there were an estimated 340 wolves (Canis lupus) (Wabakken et al. 2016) and 500 lynx (Lynx lynx) in the winter of 2015-2016 (Tovmo et al. 2016). Reindeer herders were active in the northern half of Sweden, an area with approximately 2000 brown bears (Ursus arctos) (Kindberg and Swenson 2018), 500 wolverines (Gulo gulo) (Eklund et al. 2017b), and 600 lynx (Tovmo et al. 2016). Transhumance farmers were active in Dalarna, Gävleborg, and Jämtland counties in areas with about 2000 brown bears, 200 wolverines, 500 lynx, and the occasional wolf packs (Kindberg and Swenson 2018; Tovmo et al. 2016; Eklund et al. 2017b; Wabakken et al. 2016). In Sweden, there are approximately 950,000 dogs (Swedish Board of Agriculture 2019), 420,000 sheep (Grönvall 2019), and 225,000-280,000 reindeer (Sami Parliament 2019). Between the years 2003-2018, an average of 46 dogs (range 30-68), 512 grazing livestock (range 322729), and an estimated 25,000-50,000 reindeer have been attacked or killed by large carnivores each year in Sweden (Anonymous 2012; Frank et al. 2018). Reindeer provide a main food source for carnivores in the northern part of the country (Pedersen et al. 1999; Mattisson et al. 2011, 2016).

\section{Analysis}

Recordings were transcribed in full and coded using Atlas TI 7.0. This software is designed to facilitate qualitative analysis of large amounts of audio and text data. An initial coding of the transcribed material was done by two authors (AE and MJ) to identify occurring themes in the content of the interviews. These codes were created from the material in an inductive approach and related to context of carnivore presence as well as to intervention use and its implications in husbandry practices. To assess the inter-coder agreement, the two authors coded selected parts of the interview transcripts in parallel and compared codes. The initial parallel coding generated a $67 \%$ inter-coder agreement. After discussions, a second parallel coding resulted in an $87 \%$ inter-coder agreement. The remaining disagreements were discussed between the two authors until all codes were agreed upon. All transcripts were then recoded by the first author. The initial thematic coding revealed two levels of appraisal in the discussions: one relating to owners' appraisal of carnivore presence and management and the other relating to owners' appraisal of intervention use. A thematic coding based on appraisal theory (Scherer et al. 2001) and a deductive analysis guided the themes for appraisal at these two different levels.

Thematic level 1 focuses on animal owners' appraisal of carnivore presence and management. This topic has been thoroughly investigated by, e.g., Sjölander-Lindqvist (2006, 2008, 2009), and we therefore cover it briefly to provide context for thematic level 2. Relevance on thematic level 1 relates to the relevance of carnivores as a threat to the domestic animals, implications relate to the implications of carnivore presence for the goals of animal husbandry, coping is the owners' ability to deal with the implications of the carnivore presence, and norm congruence relates to the compatibility of carnivore presence with personal and social norms.

Thematic level 2, the main focus of this paper, concerns the animal owners' appraisal of interventions intended to prevent carnivore attacks. On this level, owners appraise the relevance of intervention use, implications of using the intervention, potential for coping with these implications, and whether the use of the intervention is compatible with the owners' norms.

\section{Findings and discussion}

\section{Reasons for keeping animals}

Animal owners relate to multiple overarching reasons for keeping animals, including financial and recreational purposes. Pet dog owners and hunters with dogs particularly associate their animal husbandry with recreational values, with reference to the tranquility and pleasure of spending time in the forests with their dogs. The dogs provide friendship, but can also be a key to social groups as dog handlers can have an important role in their hunting teams and may be invited to guest hunting grounds. Dogs may in some cases provide income, but the financial purposes of animal husbandry are more prevalent among owners of sheep, reindeer, and transhumance livestock. Economic values of the animals relate to food production, but also to incomes from tourism. The relative financial importance of animal husbandry varies as there are also recreational properties to these practices, particularly among sheep owners where goals of sheep farming range from hobby holders to full-time producers. The different reasons for animal husbandry imply that there are multiple stakes at threat if animal husbandry practices are challenged. Informants also indicate that the animal husbandry represents a lifestyle associated with personal or societal values or norms, including environmental values. Hunters with dogs, sheep owners, reindeer herders, and transhumance farmers all produce meat locally. Sheep and transhumance livestock also keep the landscapes open to support biodiversity in a country which is dominated by forestry production. This achievement renders a sense of pride, illustrated by one sheep owner referring to another:

"she should get the Nobel prize just for farming all these little diminutive [land plots] far away in the forest with rocks and misery like... that should... she should have a medal!"

In line with research by, e.g., Eriksson (2011) and SjölanderLindqvist (2009), the lifestyles also relate to cultural heritage 
and a sense of responsibility in safeguarding traditional knowledge and old breeds of animals. Some transhumance farmers keep local breeds of livestock and keep their farms open to visitors to see the animals and learn about traditional dairy production. Cultural heritage is also prevalent in reindeer herding which is a practice linked to indigenous rights of the Sami people in northern Scandinavia and maintains the work of ancestors and is an integral part of Sami culture. Sheep farmers keep the countryside alive by utilizing its possibilities, and some sheep farmers are members of gene banks for rare breeds of sheep. Likewise, some hunters keep local breeds of dogs and thereby increase the viability of these traditional breeds.

The animals themselves represent a key element in fulfilling these values integrated in the owners' lifestyles, but keeping animals naturally also requires responsibility for their wellbeing (Larrère and Larrère 2000). Threats to the animals' wellbeing include diseases, injuries, and parasites. Carnivores represent an additional threat of trauma, severe injuries, or death, from which the owners must protect their animals. Animal owners can have a very close bond to their animals and there is likely a care anxiety already associated with the guardianship of animals, similar to that which parents experience towards their children (Elvin-Nowak 1999; Eriksson 2011), but this anxiety is exacerbated when carnivores are present. The carnivores represent a direct threat to the animals' life and well-being, but are also indirectly considered by the animal owners as a threat to the entire practice and the animal owners' goals of animal husbandry. For instance, sheep owners talk about loss of biodiversity and open landscapes, transhumance farmers and reindeer herders fear loss of cultural heritage and traditional knowledge, and hunters fear the loss of traditional dog breeds. Previous research suggests that the fear of losing animal husbandry is not unique to practices in Sweden (Milheiras and Hodge 2011).

\section{Appraisal of carnivore presence and emotional responses}

All interviewed groups considered carnivore presence as a relevant threat to keeping healthy domestic animals. The potential implications of carnivores on the domestic animals were also considered serious, as a carnivore attack would imply that the animals that the owner cares for may be killed, injured, or traumatized. Animal owners therefore employ various approaches to cope with the perceived or real threat from carnivores to maintain their lifestyle and activity. Pet dog owners diverge somewhat from the other groups in their coping. These owners describe a relative control over the situation: their dogs are often near the owner, also during forest walks, and the owners perceive themselves as being able to scare off carnivores, either by making noise or by merely being present. Difficulties in recruiting pet dog owners to focus groups may also reflect an irrelevance of the topic and a higher coping potential in this owner category.
The other groups of animal owners experience less control over their situation, and as their coping requires more effort, our focus is now on these owner groups. Among the remaining groups, some animal owners may be able to escape the carnivore presence and move to other geographical areas. But for most participants, this is not an option, and the use of interventions can then become important to facilitate coping with carnivore presence. Whether or not either option is possible for an animal owner to undertake depends on its congruence with the owners' norms, for instance relating to perceptions of what responsibilities are justified regarding the management of carnivore-related problems, i.e., if it should be considered the responsibility of the state or the owner. Expressed incongruence with owners' norms resembles Hill's (2004) description of the government as an "irresponsible neighbor" who is not properly looking after her/his animals (the wildlife). Ultimately, the appraisal process of each individual animal owner in response to carnivore presence will influence the strength of the emotional outcome that they experience in response to carnivore presence. Overall, this emotional outcome first and foremost relates to increased anxiety for the welfare and well-being of the domestic animals. This is similar to the findings of Frank et al. (2015) who found that fear of carnivores mainly relates to fear of attacks on domestic animals.

Negative emotions such as anxiety can represent a loss of recreational value of animal ownership and a threat to the quality of life of animal owners, which according to Manfredo (2008) may have further effects on human health. A hunter describes his loss of recreational values:

"... it's a constant anxiety in the body, and then this great pleasure of sitting in the forest and enjoying the peace... it's gone".

A sheep owner provides a similar description

"It is like belly ache when you release the animals (into the pasture)... and that anxiety can never be explained".

There are also additional emotional states of frustration and anger expressed in relation to an inability to cope with the threat, particularly when social conflicts occur. Animal owners will either have to accept their emotional state or formulate plans to respond to the situation. Planning for the most extreme scenario, they may consider quitting their practice altogether. Quitting would eliminate the relevance of carnivore presence, but would also imply a failure to meet all the goals and reasons of animal keeping in the first place. Alternatively, the relevance of carnivore presence could be reduced by the use of interventions intended to minimize the risk of an attack, and thereby facilitate coping with the carnivore presence. The owner appraisals of these interventions are the main focus of the remainder of this paper (Fig. 1). 
Fig. 1 To foster and promote the use of interventions, managers need to communicate with animal owners and resolve issues emerging in their appraisal of intervention use (i.e., its relevance, implications, owners' coping potential, and norm congruence)

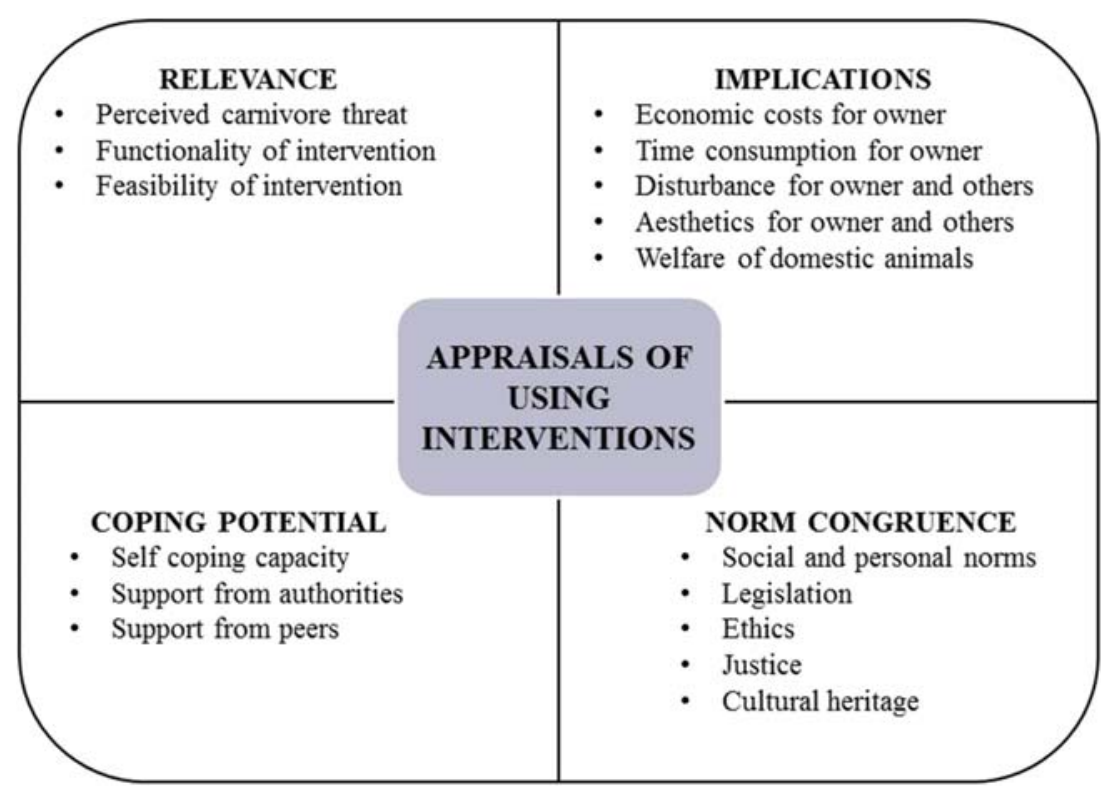

\section{Appraisal of interventions to cope with carnivore presence}

\section{Relevance of interventions relating to risk perception and functionality}

The relevance of intervention use to an animal owner depends on her/his experienced anxiety of carnivores as a threat to the domestic animals. The perceived intensity of the threat may be linked to expected emotional consequences of losing animals that the owner cares for, but also relates to the actual risk of attacks and losses. As an example, a hunter considers the relevance of using a protective vest depending on the perceived risk of an attack:

“... if you had your dog really $\mathrm{XXXX}^{1}$ bitten by a wolf, maybe killed, well then you might start re-evaluating a little. It might be a bit like that, you don't get an alarm until you have a burglar break in either".

Hunter with dog

To some extent, the risk of actual losses can be inter-related with the functionality of interventions, as is the case with reindeer. In contrast to other domestic animals, reindeer comprise the main carnivore diet within their range, so the situation requires action and makes the use of interventions relevant. However, it also impacts the functionality of interventions, as the motivation for carnivores to feed on reindeer is high and a reindeer herder states:

"if you manage to scare off a carnivore it still knows, the carnivore knows where the food is and will shortly come back, he wants to have food too".

Reindeer herder

\footnotetext{
${ }^{1}$ Profanities in quotations were replaced by XXXX.
}

Consequently, the use of some interventions will become less relevant simply because of an expected lack of effectiveness in the animal husbandry context. This functionality of interventions is generally considered on both a geographical and temporal scale. For instance, a non-removal prevention of carnivore attacks on one reindeer herd implies that carnivores must either starve or predate on a neighboring herd. Consequently, in the reindeer herding context many interventions are considered as a way of "moving the problem, not solving it". The geographical scale is also considered by the other owner groups where, as an example, removal of carnivores in predefined zones would imply that while animal owners in one area experience a reduction of carnivore numbers, animal owners in a different place will experience more carnivores to maintain the population size. Animal owners therefore expect that the effect of a zoning intervention would depend on whether you are within or outside of the predefined zone. Functionality on a temporal scale relates to the expected duration of intervention effectiveness and may depend on the quality of the intervention itself, the size and composition of carnivore populations, and on carnivore behavior.

\section{Relevance of functionality}

Animal owners judge the functionality of interventions based on scientific evaluations, or from logical reasoning around the possible ways in which an intervention could work to reduce the risk or severity of attacks. Participants express concerns about the general lack of scientific evaluations of intervention effectiveness which has also been highlighted in published scientific reviews (Eklund et al. 2017; van Eeden et al. 2018). The lack of evaluations makes it difficult to make informed decisions about interventions. A transhumance farmer expresses that: 
"it feels like the research has not been housetrained, that it's not been possible to refer to it... and to be frank there is incredibly little research on this"

Transhumance farmer

Another transhumance farmer claims:

"a lot more research is needed ... how can you say yes

[to use an intervention] when we don't know the results of the research?"

Transhumance farmer

Without the support from scientific evaluations, animal owners rely on their own reasoning and experiences to judge intervention effectiveness. Sometimes the reasoning can relate to observations of domestic animals:

“... when the herding dogs are first triggered by sheep, and it's the same with the wolf, no chance that there are any fences that help"

Sheep owner

Reasoning also involves beliefs and knowledge of wildlife behavior, for instance relating to long distance movements and individual differences among carnivores in their tendency to attack domestic animals. Some owners believe there are personality traits in carnivore behavior that influence the functionality of interventions. One group of sheep owners states:

"It is like any teenage boys, rascals that are out and cause mischief, and I think it is them that we should think about, like how to control them now?"

and

"There is no use to take the nice wolves. It is no help that nice wolves are shot"

Sheep owners

Also, the transhumance farmers provide statements of similar beliefs relating to carnivores' individual traits:

"No individual that cannot change, but you trust some individuals more than others and I even perceive it as a protection. Because I have two bear females close to the farm, it could be a protection against the wolf pack". Transhumance farmer

These examples suggest that, as a stimulus event, all carnivores are not necessarily perceived as equal threats to the animal owners, but the relevance of the threat can, at least in some cases, be context dependent.

\section{Relevance of feasibility}

Regardless of scientific evaluations or beliefs about intervention effectiveness, one thing is certain-if implementation of an intervention is not perceived as feasible by animal owners, the intervention will not be used and will have no effect (Venkatesh and Davis 2000). A transhumance farmer considers livestock-guarding dogs and disappointedly concludes that

"...potentially the method that has been most researched, which most time and money has been spent on, is the one that is least feasible"

Transhumance farmer

It is in the animal owners' everyday life that the interventions must work in order to be used. In the example of livestock guarding dogs on the transhumance summer farm, the guard dog could be a hazard to farm visitors or tourists, and during the winter, the farmer may struggle with housing the dog. Proposal of unsuitable interventions is seen as "nonchalant" and "a bit ridiculous". Asking owners to use interventions that hinder their chosen practice and require a change can be perceived as a lack of respect for the animal owner, and the interventions may be difficult for the owner to implement as many husbandry choices are steered by the landscape. In this context, animal owners highlight how their husbandry and production are adapted to the geographical location in which they operate, including the landscape, the topography, and the climate. The land that the animal owners have is the land they can use, so it is not feasible to use interventions that demand access to other geographical locations, landscape structures, or even climates. Interventions that are not considered relevant will not be considered further by animal owners, and during interviews, irrelevant interventions were refuted by a firm "No". This illustrates the importance of listening to the needs of these end users of interventions to find interventions that are functional and feasible in their practice or to be able to develop such interventions. However, even in cases when interventions are considered relevant, their use can still bring negative implications as perceived by the domestic animal owners. The use of an intervention will be considered further if intervention relevance outweighs the implications.

\section{Implications of time and money}

Implications of intervention use may come as various costs to the animal owners themselves, to other people, or to the domestic animals. All animal owners consider the economic cost of interventions, relating to the investment and implementation of the intervention through purchases of interventions, building material, or suitable land. Sheep owners consider carnivore deterring fences and ponder: 
"The fence is more worth in the balance than the production value of the animals"

Sheep owner

Economic costs also relate to investment in tools to maintain the interventions, for instance fuel and labor costs when driving to increase supervision of transhumance animals and reindeer, but also for hunters that drive to look for carnivore tracks before releasing their dogs.

In addition to economic costs, intervention establishment and maintenance can also have implications on the owners' time budget. For sheep owners, this may relate to time spent constructing a carnivore-deterring fence and clearing grass to maintain the electricity on it. The time consumption will therefore represent a labor cost that also directly links to the economic budget of animal production. Time budget implications also involve a recreational cost for hunters who spend hours searching for carnivore tracks before releasing their dogs.

\section{Implications for other people and animals}

The owners perceive that there can be social and societal implications of interventions that influence the quality of life for other people than themselves. The disturbance is in some cases purely esthetic while other interventions are considered as a health hazard for other people and animals. Light and sound deterrents, or livestock-guarding animals, are examples of interventions that are intended to be unpleasant for carnivores but which are believed unpopular with the neighbors, and which can be unpleasant or risky for people who enjoy the benefits of the legislated right to move freely in nature. Involving more people during hunts is an example of an intervention that hunters consider potentially dangerous, as hunting involves weapons.

Not least are animal owners concerned about implications of interventions to their animals' wellbeing. The interventions are intended to promote welfare by protecting the animals from carnivore attacks, but animal owners are concerned that the interventions can cause other damage. Hunting dog owners perceive welfare risks such as protective vests causing dogs to lose mobility and risk injuries from the hunted game, to bruise, or to overheat. Sheep owners, reindeer herders, and transhumance farmers experience a risk with night enclosures or calving enclosures that keep animals close together, as this practice can generate a higher parasite pressure, disease transmission, and lost feeding opportunities.

\section{Coping or quitting}

If an intervention has severe implications, perhaps even outweighing the relevance of using it, an animal owner will only be able to use it if they have the potential to cope with the implications. Choosing not to use the intervention could be argued as an alternative coping strategy, but this response moves the owner back to the first-level appraisal where they must find alternative interventions or other ways to cope with the potential implications of carnivore presence. A sheep owner who tested sound deterrents describes a situation where she had to quit using the intervention:

"The screaming is really loud and high pitched, and as there are two different noises, and because I work the shifts and, no I mean I couldn't stand it, I got nervous tendencies in the midst of everything, so I just - now these are going $\mathrm{XXXX}^{2}$ down"

Sheep owner

However, the owner may be able to cope with the implications of an intervention either by their own means or through assistance from others. Advice and support may come from peers and fellow animal owners who help each other out. A hunter, who looks for carnivore tracks before releasing his dogs, states:

"You don't have to drive until you drop... well it becomes a lot of miles, so it does, but... but you have so much support from other people like, there's a collaboration around it".

Hunter with dog

\section{The role of carnivore-managing authorities to support coping}

The governments and carnivore managing authorities have a possibility to support the animal owners' coping with intervention implications. Often, this support is given through the provision of economic support for investment in or maintenance of costly interventions, primarily giving subsidies for setting up carnivore-deterring fences to protect sheep and investment in protective vests for dogs. In some cases, sheep owners have also received help with clearing grass under the carnivore-deterring fences to maintain their functionality, and this is highly appreciated:

"The summer before last we received help, it was great... it was splendid because we have shitloads of fences... there were loads of them and they just whoosh - and they, it was great".

Sheep owner

The managing authorities often have a key role in the decision making process regarding the use of interventions, particularly in the case of hunting decisions or gaining access to knowledge about carnivore movement. Several groups express gratitude for

\footnotetext{
${ }^{2}$ Profanities in quotations were replaced by XXXX.
} 
the help they have received from the authorities, including a hunter who was given information about GPS-collared wolf movements by the staff at the county administration board (CAB):

"Everyone in the moose management area could call there $[\mathrm{a} \mathrm{CAB}]$ if they wanted to, and that's great collaboration, I think."

Hunter with dog

However, there appears to be regional and personal differences in the services provided, and the same hunter continues

"...but on the other hand, then you ask the neighboring $\mathrm{CAB}$ if they can give any information, and we've invited them to our meetings several times, but it's a flat no." Hunter with dog

The authorities can also be perceived as an obstacle when decisions are not sufficiently fast or do not meet the needs of the animal owners. A transhumance farmer provides an example:

"...there are hairs from a calf and you see the bear tracks clearly but no one can come and help you because it's Saturday"

Transhumance farmer

A reindeer herder shares a similar experience:

"We had a wolf... a genetically important wolf so protective hunting was not an alternative, and then you need to speak to three different departments at the CAB, you need to speak to the Sami Parliament, I spoke to the EPA and you get nothing... You know I was about to go $\mathrm{XXXX}^{3}$ insane... that you spend the days in the forest and the evenings on the phone, and then you get the answer: No, but now it's Friday and we can't do anything. Well, what the $\mathrm{XXXX}^{4}$ should we do? Our reindeer get killed even if it's Saturday!"

Reindeer herder

\section{Lack of coping support can generate mistrust in carnivore management}

Some animal owners express different levels of mistrust toward the managing authorities in relation to receiving support for intervention use. There are doubts about the authorities' competence and an expressed lack of trust in the authorities' interest focus which is sometimes perceived as strictly an interest in carnivore conservation. Although the interventions are intended to provide a way

\footnotetext{
3 Profanities in quotations were replaced by XXXX.

${ }^{4}$ Profanities in quotations were replaced by XXXX.
}

of coping with carnivore presence, the mistrust may also be exacerbated by the promotion of interventions that are perceived as irrelevant or have implications with which the animal owners cannot cope. In such cases, the provision of an intervention may undermine the relationship between animal owners and the authorities. As an example, a hunter doubts the authorities' judgment and initiative to distribute wolf-deterring bells free of charge:

"They say that the wolf is intelligent in some instances, and sometimes they declare it an idiot. That was with the bell, that was".

Hunter with dog

\section{Self-coping through allocation of instrumental and psychological resources}

Apart from outside support, the animal owners will also adopt personal coping strategies in response to intervention implications, such as the allocation of instrumental resources through the prioritization of time and money. These coping strategies may, in turn, create new implications. We have previously mentioned the direct implication of lost recreation, but time allocation strategies may also have impacts on sleep, reduce time spent caring for the animals, or reduce leisure or time with the family. A transhumance farmer states:

"You get other consequences from this too, you get tension in your family".

Transhumance farmer

When psychological resources are allocated to the anxiety (Flykt and Bjärtå 2008) and management of carnivore presence, this may render stress and could increase psychological pressure on animal owners, with further consequences for their quality of life.

\section{Norm congruence and risk of violating rules}

Even if interventions are considered relevant and the animal owners are able to cope with potential implications, the intervention must also be compatible with the owner's norms to be used. Social norms can relate to formal legislation. When reasoning about interventions, animal owners experience that intervention use can be limited by legislation for the rights of free movement in nature, animal welfare laws for domestic animals, and conservation regulations for management of carnivores. Social norms can also be informal and are not always congruent with the owner's personal norms. A sheep owner is concerned for her animals' welfare in relation to the instruction from the authorities to use night enclosures: 
"...then they [the $\mathrm{CAB}$ ] wanted us to bring them [the sheep] into a night enclosure, so that's what we did, but I'm going to stop doing that because the sheep don't want to. It becomes trampled, they get dirty, they don't want to be in there for seven hours..."

Sheep owner

\section{Norms relating to animal ethics}

As in the case above, personal norms can relate to those of animal welfare ethics in respect to good care and husbandry of the domestic animals in need of protection. Animal welfare ethics may also relate to guard-animal husbandry, for instance livestock guarding dogs that live with the sheep:

"You can't keep dogs like that in our country, purely ethically."

Sheep ownerand

"For me, personally, it would be really difficult because that [livestock guarding] dog would end up inside, in the bed."

Sheep owner

Norm congruence also relates to the personal norms in terms of the welfare of the carnivores themselves, such as in the case of a wolf being hazed with a helicopter from reindeer herds. One of the herders shares his story:

“...I took part in an attempt to scare away the wolf, state-sanctioned qualified cruelties to animals. I called off the attempt because I thought: yes, I am an animal owner, I keep animals and I don't want to be cruel to animals, but that was exactly what we were... It was such deep snow and things, and an ice crust and stuff. It was raining and the surface was hard and sharp so he couldn't move. So what we do when we move our reindeer is that we go first to make tracks in which the reindeer can follow, and we had to do the same for the wolf. We had to drive first with the snow mobiles to make a track. And then... 'are we now going to make tracks and move him all the way to Värmland [the core wolf area $\sim 1000 \mathrm{~km}$ south] or what's the idea?"'.

Reindeer herder

\section{Norms relating to injustice and loss of cultural heritage}

Particularly when it comes to interventions intended to prevent injuries to hunting dogs, owners argue that intervention effectiveness should be evaluated before interventions are introduced on the market. In this case, it is the individual animal owners that pay for interventions and ultimately do the testing themselves, which is seen as unjust. Justice also concerns for instance hazing of carnivores in the reindeer herding area, as well as zoning of carnivores in other parts of the country which could imply that someone else is forced to deal with the situation instead. A reindeer herder concludes:

"My problem disappears and becomes someone else's problem"

Reindeer herder

Personal norms held by the owner may overlap with social norms the owner perceives as being held by social groups or society at large, when animal owners raise ethical concerns about the risk of losing parts of the cultural heritage. Reindeer herders are concerned about moving away from the traditional reindeer herding practices if reindeer are kept in enclosures. The herders emphasize that

"although they [reindeer] are considered domestic animals, we are not farmers"

Reindeer herder

Hunters, sheep owners, and transhumance farmers are concerned about the loss of traditional breeds of livestock and dogs if they were forced to shift to breeds less prone to attacks. A hunter states:

"This [change of breed] should be weighed against the incredible work that we have put in over a hundred years to breed these hunting-culture dogs that we have" Hunter with dog

The transhumance farmers state that there is little profit in their business and that they work for the cultural environment. As a response to keeping their calves in enclosures, one farmer says:

"It's wrong that we have to change our culture and our way of keeping animals"

Transhumance farmer

\section{General conclusions}

In this study, we asked animal owners in Sweden to express their perspectives on the use of interventions to prevent carnivore attacks on their animals, with the aim of illuminating the end user perspective on intervention use. It should be noted that the perspectives come from animal owners only; no wildlife managers, authorities, researchers, policy makers, or others have been consulted for their perspectives or given the opportunity to respond to points raised in this work. The use of interventions was 
the main focus, thereby limiting the scope to potential negative impacts of carnivores on the participants. Indeed, wildlife also generates positive emotions in people, including the animal owners, who can experience benefits (e.g., interest, excitement) from carnivore presence (Manfredo 2008). Our participants were recruited with the aim of capturing the breadth of animal owners with animals at risk of carnivore attacks. By conducting several interviews, we achieved thickness in the material, i.e., the occurrence of new themes plateaued, but responses are not generalizable to all animal owners in Sweden. We present aspects of carnivore management and intervention use that surfaced during interviews, without weighting the importance or frequency of each. Instead, this work has a broad focus and provides detailed understanding of the appraisal of intervention use which is complementary to quantitative work (Eklund et al. 2020).

Using the appraisal theory of emotion (Scherer 2009) as a framework provided a relevant structure for understanding the appraisals behind emotions and reactions of animal owners in response to carnivores and carnivore management. During the initial coding, it became apparent that participants referred to two different levels of appraisal, the first relating to the animal owners' responses to carnivore presence and the second relating to their responses to the use of interventions to cope with carnivore presence. This coping response elicits the second-level appraisal process and may have consequences for various aspects of the animal owners' quality of life, including economic constraints and time consumption, animal well-being, and disturbance. Only if animal owners can cope with these implications, and if the interventions are congruent with their norms, will interventions be used. Gaining an understanding of stakeholder appraisals is important in many systems where wildlife co-occur with humans at the risk of conflict between different stakeholders. Our qualitative approach and the application of the appraisal theory of emotion (Scherer et al. 2001) could provide a framework to improve the understanding of end user appraisals and this work could thus inspire similar research elsewhere that humans and different types of wildlife co-occur.

\section{Management implications}

Although the work presented in this article relates to large carnivore management and domestic animal husbandry in Sweden, our conclusions are likely relevant also in other human-wildlife contexts. We particularly highlight how informed intervention use is fundamental to maintain trust in wildlife conservation and management. This study identifies appraisal processes on two levels, corresponding to two attitudinal objects: carnivore presence and intervention use. The two levels of appraisals can be important to keep in mind in practical work with interventions - interventions are not simply a "technical solution" to coexistence with carnivores - the interventions too are appraised by the animal owners (Redpath et al. 2013, 2015). Interventions have become an important part of carnivore conservation and management. They can provide opportunity for authorities and managers to help owners of domestic animals cope with the experienced carnivore threat, and thereby reduce the anxiety for carnivore attacks. However, to make judgments of relevant interventions animal owners request further scientific evaluations of the interventions' effectiveness, a notion which is also acknowledged in previous research (e.g., Eklund et al. 2017; Johansson and Frank 2016). As the end users of interventions, animal owners must also be able to cope with potential implications of intervention use, and once more the authorities and managers have a possibility to facilitate and support coping. This support may come in the form of economic subsidies or labor provision, and in some cases, it appears that management has already found ways to maximize the benefits of interventions to animal owners. We found much gratitude and perceived support from the authorities among animal owners with such experiences, for instance relating to financial support and maintenance for carnivore deterring fences, providing knowledge of carnivore presence, or providing deterrents free of charge. If beliefs in the authorities' benevolent motives are strengthened through this support, then trust can be established, which in turn may be important for cooperation around carnivore management and intervention use (Balliet and Van Lange 2013; Simpson 2007).

However, the provision or promotion of interventions can also undermine the relationship between animal owners and carnivore management if animal owners presented with interventions they find irrelevant, that imply implications with which they cannot cope, or that are incongruent with their norms. In such cases, the provision of interventions could make managers appear incompetent or generate negative emotions in the animal owners, including frustration or anger (Johansson and Frank 2016). To avoid jeopardizing any existing trust in management or conservation, it is therefore beneficial to analyze the intended function of the support. In our results section, a hunter refers to a case where authorities provided allegedly wolf-deterring bells free of charge to hunters with dogs. In this case, the authorities were providing financial support through a very cheap intervention, i.e., support coping with a small economic implication. The particular animal owner did not find the intervention relevant to use in the first place as he did not believe it was an effective repellent but rather an attractant for wolves. As such, the management was perceived as negligent or incompetent rather than as a support. 
Overall, gaining a greater understanding of animal husbandry practices may help authorities and managers, or researchers, focus on interventions that are more relevant to the owners. Without a good understanding of the animal husbandry practices, there is a risk of fueling conflict. A greater respect and understanding for owner perspectives and practices, and a willingness and ability to listen and learn from owner experiences, is immensely important for the social trust in carnivore management. Not least should we acknowledge the importance of the emotional responses that these topics readily generate in people, the primary stakeholders included. Positive emotions importantly and positively influence interpersonal relationships, communication, consensus, and conflict resolutions, while negative emotions inhibit such outcomes (Manfredo 2008). Although we, as non-animal owners, may be able to gain some understanding of the situation of animal owners, it will be hard to fully experience their emotional responses to it. If a non-animal owner is to appraise the animal owner's situation, they must obtain as complete information about the situation as possible, and be attentive to the information communicated (Wondra and Ellsworth 2015). Humility, an ability to understand concerns and emotions of the individual, and acknowledgement of animal owners' experiences are of vital importance to facilitate development of social trust and empathetic dialog between different stakeholders in the future.

Acknowledgments The authors would like to thank and acknowledge the generosity of all focus group participants. We would also like to thank our contact persons who helped us recruit participants.

Funding information Open access funding provided by Swedish University of Agricultural Sciences. This work was supported by the Swedish Research Council FORMAS, under Grant 2013-817 and the Swedish University of Agricultural Sciences.

\section{Compliance with ethical standards}

Conflict of interest The authors declare that they have no conflict of interest.

Ethical approval The study was considered compliant with the code for research involving humans. A potential discrepancy related to handling of sensitive personal data of reindeer herders. Although reindeer herding represent a work practice, it is closely tied to cultural heritage and rights of the indigenous Sami people in northern Scandinavia. The ethical board in Uppsala, Sweden, Dnr 2017/259, approved the study before recruitment of reindeer herders to interviews.

Open Access This article is licensed under a Creative Commons Attribution 4.0 International License, which permits use, sharing, adaptation, distribution and reproduction in any medium or format, as long as you give appropriate credit to the original author(s) and the source, provide a link to the Creative Commons licence, and indicate if changes were made. The images or other third party material in this article are included in the article's Creative Commons licence, unless indicated otherwise in a credit line to the material. If material is not included in the article's Creative Commons licence and your intended use is not permitted by statutory regulation or exceeds the permitted use, you will need to obtain permission directly from the copyright holder. To view a copy of this licence, visit http://creativecommons.org/licenses/by/4.0/.

\section{References}

Agarwala M, Kumar S, Treves A, Naughton-Treves L (2010) Paying for wolves in Solapur, India and Wisconsin, USA: comparing compensation rules and practice to understand the goals and politics of wolf conservation. Biol Conserv 143:2945-2955

Anonymous (2012) Mål för rovdjuren. State Public Reports SOU 2012: 22, Department of the Environment, Stockholm, Sweden

Austin Z, Smart JCR, Yearly S, Irvine RJ, White PCL (2010) Identifying conflicts and opportunities for collaboration in the management of a wildlife resource: a mixed-methods approach. Wildl Res 37:647657

Balliet D, Van Lange PAM (2013) Trust, conflict, and cooperation: a meta-analysis. Psychol Bull 139:1090-1112

Barnosky AD, Matzke N, Tomiya S, Wogan GO, Swartz B, Quental TB, Marshall C, McGuire J, Lindsey EL, Maguire KC, Mersey B, Ferrer EA (2011) Has the Earth's sixth mass extinction already arrived? Nature 471:51-57

Bruskotter JT, Vaske JJ, Schmidt RH (2009) Social and cognitive correlates of Utah residents' acceptance of the lethal control of wolves. Hum Dimens Wildl 14:119-132

Carter NH, Riley SJ, Liu J (2012) Utility of a psychological framework for carnivore conservation. Oryx 46:525-535

Dirzo R, Young HS, Galetti M, Ceballos G, Isaac NJB, Collen B (2014) Defaunation in the Anthropocene. Science 345:401-406

Eklund A, López-Bao JV, Tourani M, Chapron G, Frank J (2017) Limited evidence on the effectiveness of interventions to reduce livestock predation by large carnivores. Sci Rep 7:2097

Eklund A, Mattisson J, Höglund L, Tovmo M (2017b) Inventering av järv 2017. Beståndsstatus för stora rovdjur i Skandinavien. Report from SLU Viltskadecenter 3-2017, Grimsö, Sweden

Eklund A, Johansson M, Flykt A, Andrén H, Frank J (2020) Believed effect - a prerequisite but not a guarantee for acceptance of carnivore management interventions. Biol Conserv 241:108251

Elvin-Nowak Y (1999) The meaning of guilt: a phenomenological description of employed mothers' experiences of guilt. Scand J Psychol 40:73-83

Eriksson C (2011) What is traditional pastoral farming? The politics of heritage and 'real values' in Swedish summer farms (fäbodbruk). Pastoralism Res Policy Pract 1:25

Flykt A, Bjärtå A (2008) The time course of resource allocation in spiderfearful participants during fear reactions. Cognit Emot 22:13811400

Frank J, Johansson M, Flykt A (2015) Public attitude towards the implementation of management actions aimed at reducing human fear of brown bears and wolves. Wildl Biol 21:122-130

Frank J, Månsson J, Höglund L (2018) Viltskadestatistik 2017 Skador av fredat vilt på tamdjur, hundar och gröda. Report from SLU Viltskadecenter 2018-1, Riddarhyttan, Sweden

Grönvall A (2019) Number of sheep and holdings with sheep in December 2018. Statistical Report 2019:02. Statens Jordbruksverk, Jönköping

Harper D (2002) Talking about pictures: a case for photo elicitation. Vis Stud 17:13-26

Hill CM (2004) Farmers' perspectives of conflict at the wildlifeagriculture boundary: some lessons learned from African subsistence farmers. Hum Dimens Wildl 9:279-286 
Jacobs MH, Vaske JJ, Teel TL, Manfredo M (2013) Human dimensions of wildlife. In: Steg L, van den Berg AE, de Groot JIM (eds) Environmental psychology, and introduction. The British Psychological Society and Wiley, Chichester, pp 77-86

Jacobs MH, Vaske JJ, Sijtsma MTJ (2014) Predictive potential of wildlife value orientations for acceptability of management interventions. J Nat Conserv 22:377-383

Johansson M, Frank J (2016) The impact of access to an ultrasonic scaring device on human fear of wolves. Wildl Biol 22:29-36

Johansson M, Karlsson J, Pedersen E, Flykt A (2012) Factors governing human fear of brown bear and wolf. Hum Dimens Wildl 17:58-74

Johansson Ö, Rauset GR, Samelius G, McCarthy T, Andrén H, Tumursukh L, Mishra C (2016) Land sharing is essential for snow leopard conservation. Biol Conserv 203:1-7

Kindberg J, Swenson JE (2018) Björnstammens storlek i Sverige 2017. Skandinaviska björnprojektet report 2018-3, Skandinaviska Björnprojektet, Orsa

Koval MH, Mertig AG (2010) Attitudes of the Michigan public and wildlife agency personnel toward lethal wildlife management. Wildl Soc Bull 32:232-243

Larrère C, Larrère R (2000) Animal rearing as a contract? J Agric Environ Ethics 12:51-58

Leventhal IL, Scherer KR (1987) The relationship of emotion to cognition: a functional approach to semantic controversy. Cognit Emot 1: $3-28$

Manfredo MJ (2008) Who cares about wildlife? Springer Science, New York

Mattisson J, Odden J, Nilsen EB, Linnell JDC, Persson J, Andrén H (2011) Factors affecting Eurasian lynx kill rates on semi-domestic reindeer in northern Scandinavia: can ecological research contribute to the development of a fair compensation system? Biol Conserv 144:3009-3017

Mattisson J, Rauset GR, Odden J, Andrén H, Linnell JDC, Persson J (2016) Predation or scavenging? Prey body condition influences decision-making in a facultative predator, the wolverine. Ecosphere 7. https://doi.org/10.1002/ecs2.1407

Milheiras S, Hodge I (2011) Attitudes towards compensation for wolf damage to livestock in Viana do Castelo, north of Portugal. Innov Eur J Soc Sci Res 24:333-351

Naughton-Treves L, Grossberg R, Treves A (2003) Paying for tolerance: rural citizens' attitudes toward wolf depredation and compensation. Conserv Biol 17:1500-1511

Parker A, Tritter J (2006) Focus group method and methodology: current practice and recent debate. Int J Res Method Educ 29:23-37

Pedersen VA, Linnell JDC, Andersen R, Andrén H, Lindén M, Segerström P (1999) Winter lynx Lynx lynx predation on semidomestic reindeer Rangifer tarandus in northern Sweden. Wildl Biol 5:203-211

Redpath SM, Young J, Evely A, Adams WM, Sutherland WJ, Whitehouse A, Amar A, Lambert RA, Linnell JD, Watt A, Gutiérrez RJ (2013) Understanding and managing conservation conflicts. Trends Ecol Evol 28:100-109

Redpath SM, Bhatia S, Young J (2015) Tilting at wildlife: reconsidering human-wildlife conflict. Oryx 49:222-225

Robson C (2011) Real world research, 3rd edn. Wiley
Sami Parliament (2019) Rennäringen i Sverige. Available from https:// www.sametinget.se/rennaring sverige. Accessed 2019-11-14

Scherer K (2009) The dynamic architecture of emotion: evidence for the component process model. Cognit Emot 23:1307-1351

Scherer KR, Schorr A, Johnstone T (eds) (2001) Series in affective science. Appraisal processes in emotion: theory, methods, research. Oxford University Press, New York

Simpson JA (2007) Psychological foundations of trust. Curr Dir Psychol Sci 16:264-268

Sjölander-Lindqvist A (2006) "Den är ju inte i fårhagen på studiebesök" Om lokala perspektiv och uppfattningar om varg och svensk rovdjurspolitik. CEFOS Report 2006:1, Göteborgs Universitet, Gothenburg, Sweden

Sjölander-Lindqvist A (2008) Local identity, science and politics indivisible: the Swedish wolf controversy deconstructed. J Environ Policy Plan 10:71-94

Sjölander-Lindqvist A (2009) Social-natural landscape reorganised Swedish Forest-edge farmers and wolf recovery. Conserv Soc 7: $130-140$

Sjölander-Lindqvist A, Johansson M, Sandström C (2015) Individual and collective responses to large carnivore management: the roles of trust, representation, knowledge spheres, communication and leadership. Wildl Biol 21:175-185

Swedish Board of Agriculture (2019) Statistik ur hundregistret. Available from http://www.jordbruksverket.se/amnesomraden/djur/ olikaslagsdjur/hundarochkatter/markochregistreradinhund/statistik. 4.45fb0f14120a3316ad78000672.html. Accessed 2019-11-14

Tovmo M, Zetterberg A, Brøseth H, Andrén H (2016) Inventering av lodjur 2016. Beståndsstatus för stora rovdjur i Skandinavien, Report from SLU Viltskadecenter 2-2016, Grimsö

Treves A, Wallace RB, Naughton-Treves L, Morales A (2006) Comanaging human-wildlife conflicts: a review. Hum Dimens Wildl 11:383-396

Treves A, Krofel M, McManus J (2016) Predator control should not be a shot in the dark. Front Ecol Environ 14:380-388

van Eeden L et al (2018) Carnivore conservation needs evidence-based livestock protection. PLoS Biol 16:e2005577

Venkatesh V, Davis FD (2000) A theoretical extension of the technology acceptance model: four longitudinal field studies. Manag Sci 46: 186-204

Wabakken P, Svensson L, Maartmann E, Åkesson M, Flagstad Ø (2016) Bestandsovervåking av ulv vinteren 2015-2016. Bestandsstatus for store rovdyr i Skandinavia, Report from SLU Viltskadecenter 12016, Grimsö

Wondra JD, Ellsworth PC (2015) An appraisal theory of empathy and other vicarious emotional experiences. Psychol Rev 122:411-428

Woodroffe R, Thirgood S, Rabinowitz A (eds) (2005) People and wildlife: conflict or coexistence. Cambridge University Press, Cambridge

Zabel A, Holm-Müller K (2008) Conservation performance payments for carnivore conservation in Sweden. Conserv Biol 22:247-251

Publisher's note Springer Nature remains neutral with regard to jurisdictional claims in published maps and institutional affiliations. 